\title{
Visual loss and optic nerve head swelling in thiamine deficiency without prolonged dietary deficiency
}

This article was published in the following Dove Press journal:

Clinical Ophthalmology

22 May 2014

Number of times this article has been viewed

\section{Sean M Gratton \\ Byron L Lam}

Bascom Palmer Eye Institute, University of Miami, Miller School of Medicine, Miami, FL, USA
Correspondence: Sean Gratton

Bascom Palmer Eye Institute, University of Miami, Miller School of Medicine, 900 NW 17th St, Miami, FL 33। 36, USA $\mathrm{Tel}+$ I 816726 I073

Fax + I 3054825239

Email seangratton@gmail.com

\begin{abstract}
Visual loss due to optic neuropathy is a rare manifestation of thiamine deficiency. We report a case of a 39-year-old woman with a body mass index (BMI) of $29 \mathrm{~kg} / \mathrm{m}^{2}$ who developed visual loss and bilateral optic nerve head swelling after a short, self-limited gastrointestinal illness. She was disoriented and inattentive and had absent ankle jerk reflexes, diminished sensation in both legs below the knees, and marked truncal ataxia. Magnetic resonance imaging (MRI) showed increased T2-signal in the medial thalami and mammillary bodies. The serum thiamine level was $8 \mathrm{nmol} / \mathrm{L}$ (normal 8-30). The diagnosis of thiamine deficiency was made, and the patient's vision and neurologic symptoms improved significantly with intramuscular thiamine treatment. Thiamine deficiency can occur in the absence of an obvious predisposing factor such as alcoholism or low body weight. The clinician must be aware of the factors that govern vitamin availability and maintain a high index of suspicion to make the diagnosis in such cases.
\end{abstract}

Keywords: optic neuropathy, nutritional deficiency

\section{Introduction}

Thiamine is a water-soluble vitamin that plays a critical role in glucose metabolism by serving as an essential cofactor for several enzymes. ${ }^{1}$ The central nervous system is almost completely dependent on glucose metabolism for energy $\mathrm{y}^{2,3}$ and is therefore susceptible to thiamine deficiency. Classically, thiamine deficiency manifests as the triad of Wernicke encephalopathy: acute confusional state, ataxia, and ophthalmoparesis. ${ }^{4}$ Visual loss with optic disc swelling is a rare manifestation of thiamine deficiency ${ }^{1,2,5-8}$ that was included in Wernicke's original description of the disease that now bears his name. ${ }^{4}$ We present a case of visual loss with optic disc swelling that occurred in the absence of an obvious inciting factor, such as alcoholism or bariatric surgery, and review the factors that govern thiamine bioavailability.

\section{Case report}

A 39-year-old woman presented with 1 week of progressive "foggy" vision preceded by 3 weeks of self-resolving diarrhea and vomiting of unknown etiology. One week after the onset of visual loss, she developed burning pain in both lower legs, reaching up to her knees. She had a history of nonalcoholic steatohepatitis, a body mass index (BMI) of $29 \mathrm{~kg} / \mathrm{m}^{2}$, and no unusual dietary habits. Visual acuity was 2/200 in the right eye and 4/200 in the left eye, with bilateral centrocecal scotomas on Goldmann visual field testing (Figure 1A). The optic nerves had edema with pallor superiorly and inferiorly, along with peripapillary hemorrhages at 2:00 in the left eye (Figure 2A). 
A

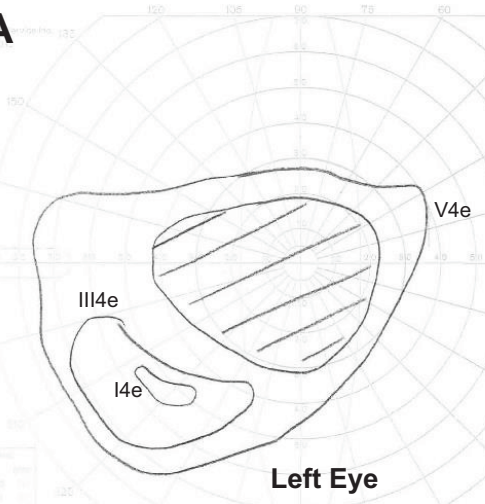

B

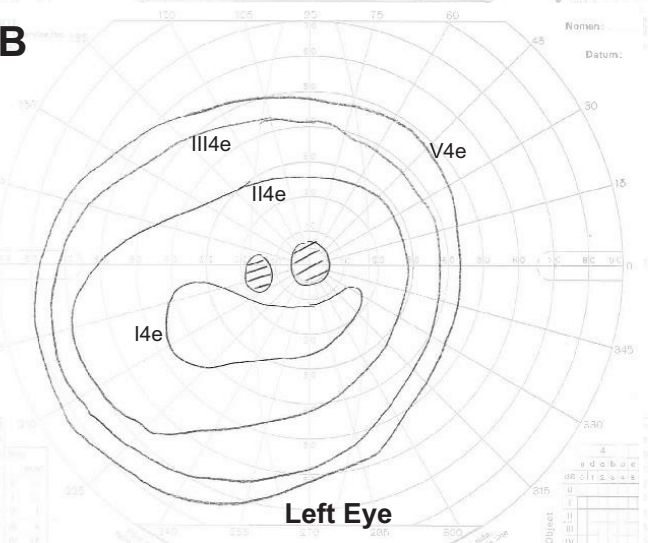

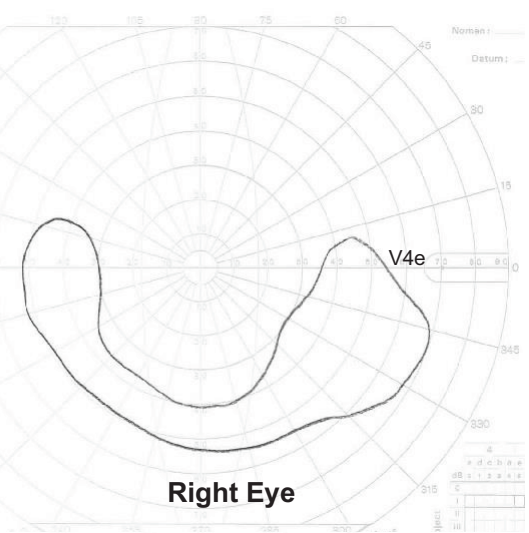

Right Eye

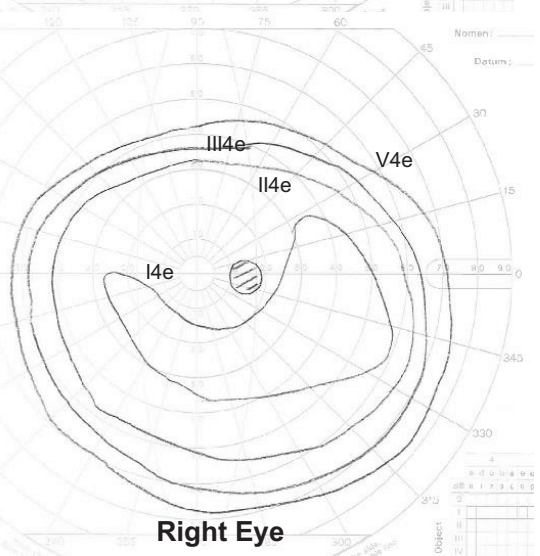

Figure I Goldmann perimetry of both eyes.

Notes: (A) On initial presentation, there were large centrocecal scotomas in both eyes. (B) Two days after thiamine replacement, the visual fields in both eyes had expanded significantly.

She was disoriented and inattentive, with gaze-evoked nystagmus. She had absent ankle jerk reflexes, diminished sensation below the knees in both lower legs, and marked truncal ataxia. Lumbar puncture opening pressure was $15 \mathrm{~cm}$ water, and the cerebrospinal fluid (CSF) constituents were normal. Magnetic resonance imaging (MRI) showed increased T2-signal in the medial thalami and mammillary bodies (Figure 3). The diagnosis of Wernicke encephalopathy was made based on her clinical presentation and radiological findings.

The serum thiamine level was $8 \mathrm{nmol} / \mathrm{L}$ (normal 8-30), and thiamine, $100 \mathrm{mg}$ intramuscularly daily for 2 weeks, was instituted. After 2 days, her visual acuity improved to 20/25 (right eye) and 20/50 (left eye), and her visual field expanded significantly in both eyes (Figure 1B). Her mental status improved to baseline, and her nystagmus resolved. The optic disc swelling improved over the next month (Figure 2B), but the ataxia and lower extremity dysesthesia persisted.

\section{Discussion}

Optic neuropathy is a relatively uncommon manifestation of thiamine deficiency. ${ }^{1,2,-9}$ Visual loss is often severe, including loss of light perception, and significant visual improvement may occur after thiamine replacement. ${ }^{5}$ Optic disc edema is present in most cases, ranging from peripapillary retinal nerve fiber layer thickening with retinal hemorrhage ${ }^{8}$ to marked optic disc swelling with peripapillary hemorrhage ${ }^{6}$ to pale edema. ${ }^{2}$

Thiamine deficiency is frequently described to be a consequence of specific conditions that cause prolonged dietary deficiency, such as chronic alcoholism or gastric bypass surgery. ${ }^{1,2,5-7}$ Our patient shows that thiamine deficiency can occur in the absence of such a condition. The availability of thiamine or any vitamin is dependent on its intake, storage, and usage. An imbalance between these three factors can occur without a severe or prolonged dietary disruption. Even a healthy individual can become thiamine-deficient after only a brief period of nutritional imbalance. ${ }^{9}$

Thiamine is found naturally in animal and plant products, such as yeast, whole grains, legumes, and pork. In the United States, flour has been enriched with thiamine since the 1930s. Despite the multiplicity of sources, few foods are actually rich in thiamine, and thiamine is absent from fats, oils, and refined sugars, ${ }^{10}$ which are becoming an increasingly large 

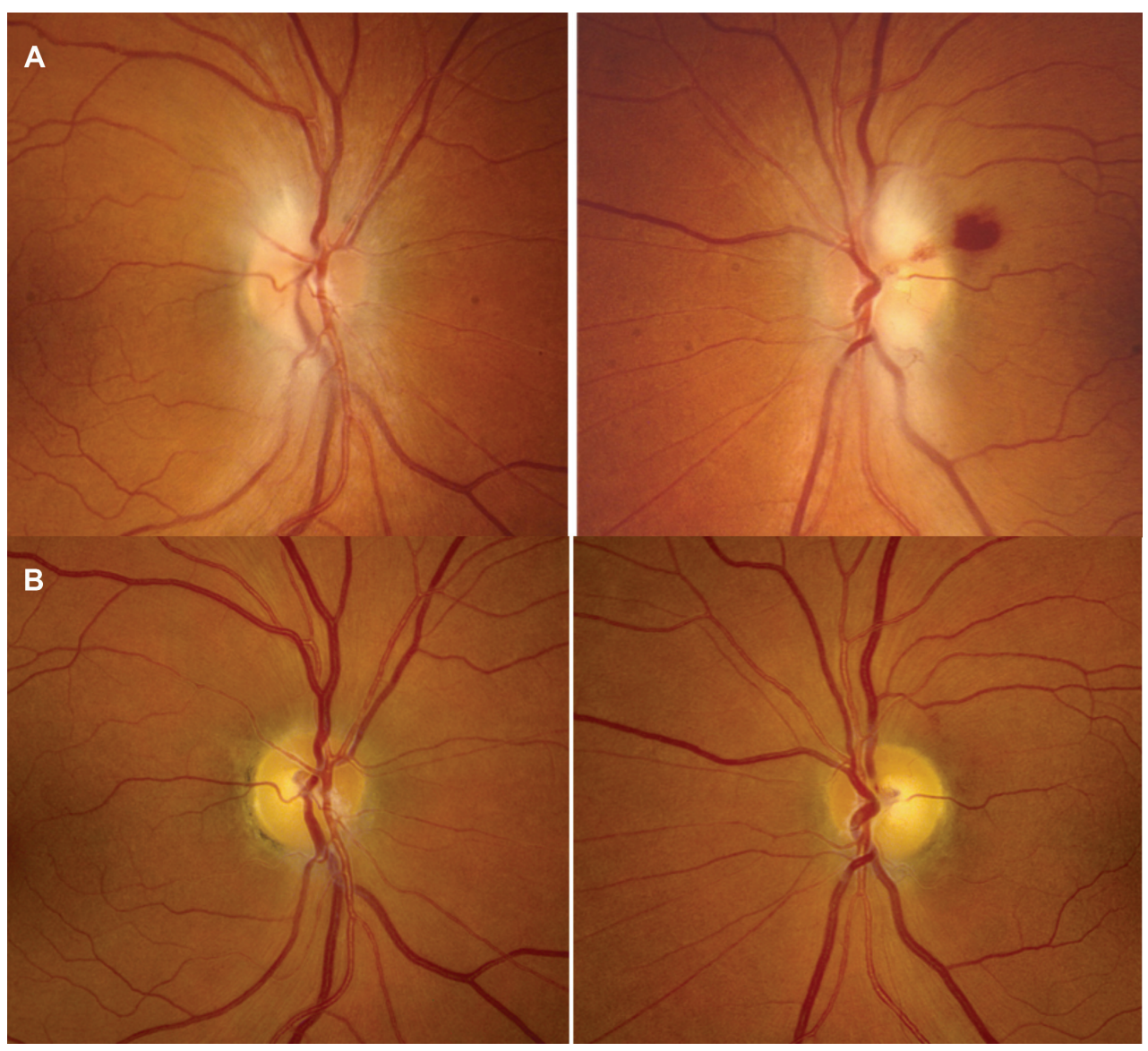

Figure 2 Fundus photographs of both eyes.

Notes: (A) On initial presentation, both optic nerves had pale blurring of the disc margins superiorly and inferiorly, with peripapillary hemorrhage in the left eye. (B) One month later, the swelling had resolved, with only mild prominence of the retinal nerve fiber layer remaining bilaterally.

portion of Western diets. The body's requirement for thiamine is directly related both to total caloric intake and to carbohydrate intake, where high caloric and carbohydrate intake leads to a higher requirement for thiamine. ${ }^{9}$ The modern American diet is high in fats and refined sugars as well as high in calories and carbohydrates. This type of diet is thiamine-poor, while at the same time increases the demand for thiamine. ${ }^{9}$ High caloric intake, as seen in obesity, does not equate to adequate thiamine intake. ${ }^{10}$ Carrodeguas et al examined the serum of obese patients undergoing bariatric surgery and found that $15.5 \%$ were thiamine-deficient preoperatively. ${ }^{10}$

Thiamine is stored in skeletal muscle, cardiac muscle, liver, kidney, and brain. The whole body store of thiamine is approximately $30 \mathrm{mg},{ }^{10}$ which is maintained with a daily requirement of $1.5 \mathrm{mg}$. Liver damage may reduce the capacity to store vitamins, including thiamine, in the liver. ${ }^{11}$ When the demand for thiamine exceeds intake, stores are depleted and deficiency occurs. Demand is increased in pregnancy, lactation, fever, illness, and perioperatively. ${ }^{10}$ These hypermetabolic states require large amounts of thiamine, as a cofactor for enzymes, to meet metabolic demands. Total cessation of thiamine intake would result in deficiency within 3 weeks. ${ }^{6,7,9}$ This timing is supported experimentally in both humans and animals. ${ }^{11}$ An individual with marginal stores of thiamine would experience deficiency earlier. ${ }^{9}$

Several elements in our patient's history combined to create an unfavorable balance of the factors that govern vitamin bioavailability. Her thiamine intake was diminished, in the long term, by a diet rich in fatty, refined foods and, in the short term, by a gastrointestinal illness limiting oral intake. Her body storage of thiamine was likely limited from the outset due to preexisting liver disease in the form of nonalcoholic steatohepatitis. Her body's demand for thiamine was high because of her high-carbohydrate, highcalorie diet as well as her period of illness and elevated metabolic demand. Thiamine $100 \mathrm{mg}$ intramuscularly daily effectively met her body's demand for thiamine and resulted in a dramatic improvement in her visual function, ataxia, and mental status. Some authors recommend administration of 


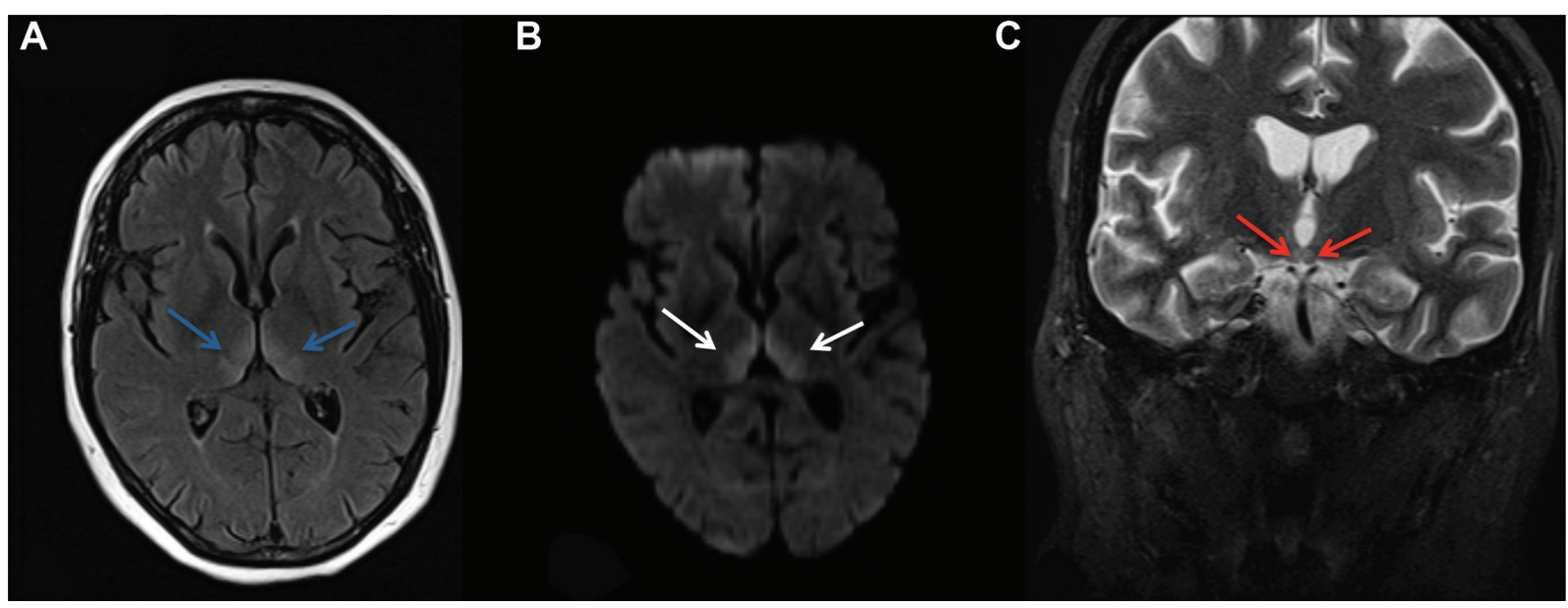

Figure 3 MRI scans of the patient's brain on initial presentation.

Notes: On MRI, the medial thalami showed increased T2-signal bilaterally as shown on both (A) FLAIR sequences (blue arrows) and (B) diffusion-weighted (white arrows) sequences. (C) The mammillary bodies showed increased T2-signal bilaterally (red arrows).

Abbreviations: FLAIR, fluid-attenuated inversion recovery; MRI, magnetic resonance imaging.

a larger dose of thiamine, perhaps greater than $500 \mathrm{mg}$ per day intravenously. ${ }^{12}$

\section{Conclusion}

Visual loss due to optic neuropathy is a rare manifestation of thiamine deficiency. Clinicians should bear in mind the balance of intake, storage, and usage of vitamins, when evaluating patients suspected of nutritional deficiency diseases of the central nervous system. Maintaining a high index of suspicion will allow for prompt recognition of these treatable conditions.

\section{Disclosure}

The authors report no conflicts of interest in this work.

\section{References}

1. Spinazzi M, Angelini C, Patrini C. Subacute sensory ataxia and optic neuropathy with thiamine deficiency. Nat Rev Neurol. 2010; 6(5):288-293.

2. van Noort BA, Bos PJ, Klopping C, Wilmink JM. Optic neuropathy from thiamine deficiency in a patient with ulcerative colitis. Doc Ophthalmol. 1987;67(1-2):45-51.

3. Hoyt CS, 3rd. Vitamin metabolism and therapy in ophthalmology. Surv Ophthalmol. 1979;24(3):177-190.
4. Victor M, Adams RD, Collins GH. The Wernicke-Korsakoff Syndrome: A Clinical and Pathological Study of 245 patients, 82 with Post-Mortem Examinations. Philadelphia: F. A. Davis Company; 1971.

5. Li JM, Rucker JC. Irreversible optic neuropathy in Wernicke encephalopathy and leber hereditary optic neuropathy. J Neuroophthalmol. 2010;30(1):49-53.

6. Kulkarni S, Lee AG, Holstein SA, Warner JEA. You are what you eat. Surv Ophthalmol. 2005;50(4):389-393.

7. Yeh WY, Lian LM, Chang A, Cheng CK. Thiamine-deficient optic neuropathy associated with Wernicke's encephalopathy in patients with chronic diarrhea. J Formos Med Assoc. 2013;112(3):165-170.

8. Bohnsack BL, Patel SS. Peripapillary nerve fiber layer thickening, telangiectasia, and retinal hemorrhages in Wernicke encephalopathy. J Neuroophthalmol. 2010;30(1):54-58.

9. Sechi G, Serra A. Wernicke's encephalopathy: new clinical settings and recent advances in diagnosis and management. Lancet Neurol. 2007;6(5):442-455.

10. Carrodeguas L, Kaidar-Person O, Szomstein S, Antozzi P, Rosenthal R. Preoperative thiamine deficiency in obese population undergoing laparoscopic bariatric surgery. Surg Obes Relat Dis. 2005;1(6):517-522; discussion 522.

11. Thomson AD. Mechanisms of vitamin deficiency in chronic alcohol misusers and the development of the Wernicke-Korsakoff syndrome. Alcohol Alcohol Suppl. 2000;35(1):2-7.

12. Thomson AD, Cook CC, Touquet R, Henry JA; Royal College of Physicians, London. The Royal College of Physicians report on alcohol: guidelines for managing Wernicke's encephalopathy in the accident and Emergency Department. Alcohol Alcohol. 2002;37(6):513-521.

\section{Clinical Ophthalmology}

\section{Publish your work in this journal}

Clinical Ophthalmology is an international, peer-reviewed journal covering all subspecialties within ophthalmology. Key topics include: Optometry; Visual science; Pharmacology and drug therapy in eye diseases; Basic Sciences; Primary and Secondary eye care; Patient Safety and Quality of Care Improvements. This journal is indexed on Submit your manuscript here: http://www.dovepress.com/clinical-ophthalmology-journal
PubMed Central and CAS, and is the official journal of The Society of Clinical Ophthalmology (SCO). The manuscript management system is completely online and includes a very quick and fair peer-review system, which is all easy to use. Visit http://www.dovepress.com/ testimonials.php to read real quotes from published authors. 